\title{
Nitrogen-Rich Polymers \\ as Candidates for Energetic Applications
}

\author{
Eric Pasquinet
}

Additional information is available at the end of the chapter

http://dx.doi.org/10.5772/46245

This chapter is dedicated to the memory of Etienne Kosciusko-Morizet

\section{Introduction}

The design of new energetic molecules is based on compounds exhibiting a high density and an elevated heat of formation. These fundamental properties, achieved through the presence of numerous nitrogen atoms and/or explosophoric groups, ensure high performance levels that can be useful in target applications such as explosives, propellants or gas generators.

The same basics also apply when considering the use of polymers, instead of single molecules, as energetic ingredients. However, the quest for high densities and heats of formation appears somewhat more challenging in the case of polymers, since the polymerization process often requires specific chemical functions that may be detrimental to the desired energetic properties. Currently, the most commonly used polymers in the field get their energetic content only from explosophoric groups: $\mathrm{NO}_{2}$ for polyNIMMO (polynitratomethyl methyloxetane) or polyGLYN (polyglycidyl nitrate), N3 for GAP (glycidyl azide polymer), to name a few. This survey gives an overview of research efforts that have been devoted to the synthesis of macromolecules with high nitrogen contents. Such a unique property is expected to produce materials with particularly elevated heats of formation, thus making them very valuable in the field of energetic compounds.

Azaheterocycles are obviously suitable scaffolds for achieving nitrogen-rich polymers. Tetrazole-, tetrazine-, triazole- and triazine-based materials are considered here. Three methodologies have been identified as the main routes for obtaining the target polymers: polymerization of vinylazaheterocycles, incorporation of the desired azaheterocycle in a preformed macromolecular architecture and polycondensation. 


\section{Tetrazole-based polymers}

\subsection{Polymerization of vinyltetrazoles}

During the last decade, two major papers have reviewed the synthesis and polymerization of vinyltetrazoles, and together they present an extensive literature coverage $\left[{ }^{1}{ }^{2}\right]$.

\subsubsection{Synthesis of C-vinyltetrazoles}

Polymerization of the starting and/or target vinyl compound is a major concern in the reaction of acrylonitrile with sodium azide leading to $C$-vinyltetrazole (5-vinyltetrazole) 2 . Masking of the double bond of acrylonitrile 1 through addition of dimethylamine [ $\left.{ }^{3}\right]$ or hydrogen chloride [ $\left.{ }^{4}\right]$ circumvents this problem and renders the process more efficient (Figure 1).

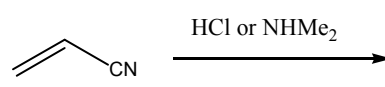

1

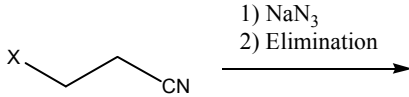

$\mathrm{X}=\mathrm{Cl}, \mathrm{NMe}_{2}$

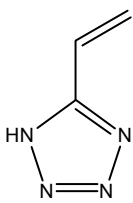

2

Figure 1.

\subsubsection{Synthesis of N-vinyltetrazoles}

Two main strategies have been used for the synthesis of $N$-vinyltetrazoles. The first one involves alkylation of the tetrazole $\mathrm{N}-\mathrm{H}$ with a functionalized ethyl chain, followed by elimination. The second one is the catalyzed direct vinylation with vinylacetate or butylvinylether. Recently, a variant of the first approach, using dibromoethane as the alkylating agent, has been developed [5]. This method appears now as the method of choice, since it is a one-step, high-yielding procedure that only needs readily available, non-toxic chemicals. In the majority of cases, a mixture of 1- and 2-vinyltetrazole are produced and selectivity depends on the 5 -substituent (Figure 2).

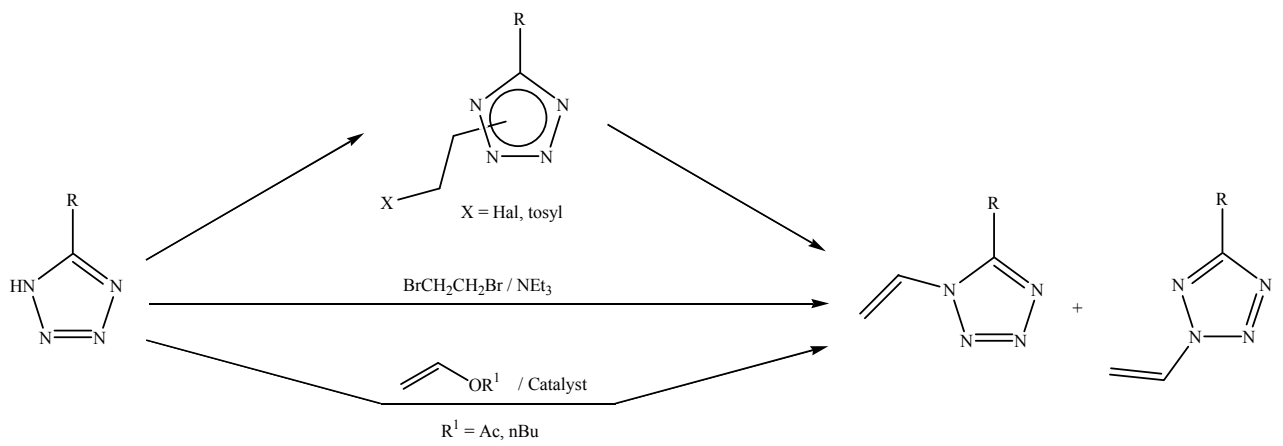

Figure 2. 


\subsubsection{Synthesis of divinyltetrazoles}

Following the above-mentioned strategies, divinyltetrazole compounds have been obtained. Vinylation of 5-vinyltetrazole gave a mixture of 1,5- and 2,5-divinyltetrazole 3a-b in a 1/2.32.4 ratio $\left[{ }^{5},{ }^{6}\right]$. In the vinylation of 5,5'-methylenebis(2-vinyltetrazole) 4 , only 2 of the 3 possible isomers were isolated, as the 1,1'-divinyl compound was not detected [5]. Such divinyl products could be useful as nitrogen-rich cross-linkers (Figure 3).
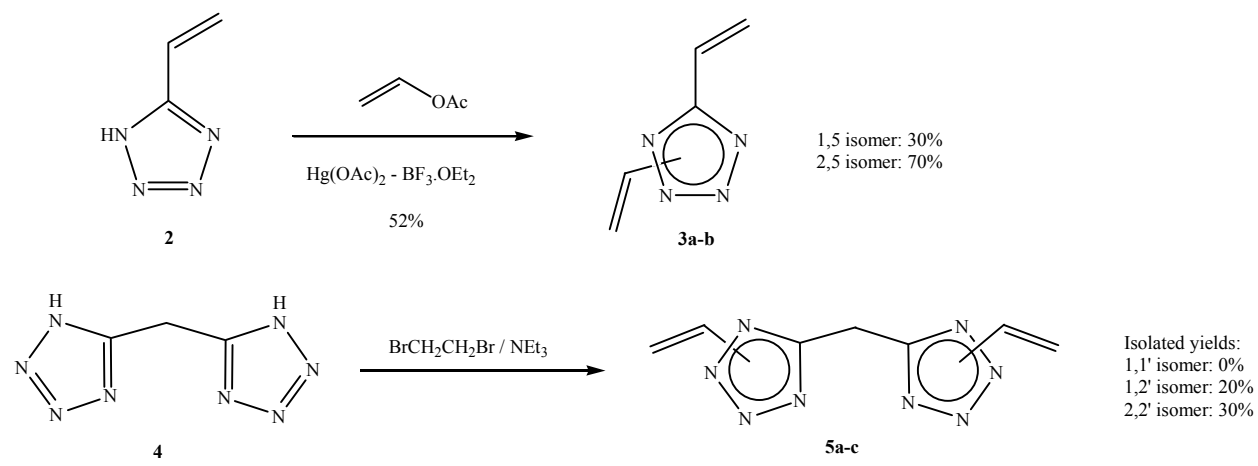

Figure 3.

\subsubsection{Polymerization of C-vinyltetrazoles}

5-Vinyltetrazoles are readily involved in free-radical polymerization (Figure 4). A comparison between $\mathrm{C}$ - and $\mathrm{N}$-vinyltetrazoles shows that the former are more active in such processes. A number of reaction media have been used for the polymerization of 5vinyltetrazoles, and it was shown that the activity was enhanced in more polar solvents, especially in water. Molecular weights also increased in aqueous systems. This trend prompted a polymerization study in ionic solvents. Of the various ionic liquids (ILs) tested, only 1-methyl-3-propylimidazolium bromide gave rise to decent yields. Other ILs gave low yields or even decomposition of the tetrazole ring [ $\left.{ }^{7}\right]$.

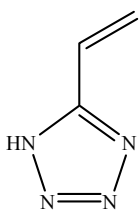

2

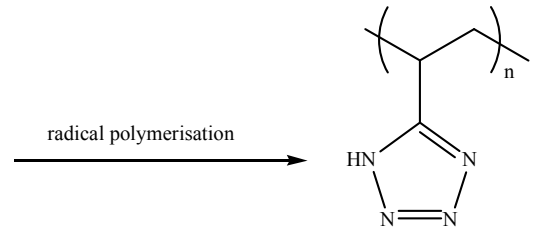

$6 \quad 58.3 \% \mathrm{~N}$

Figure 4.

Poly-5-vinyltetrazole 6 contains 58.3\% nitrogen, which clearly makes it a high-nitrogen compound. However, it seems that its $N$-vinyl congener has been favored for industrial applications. 


\subsubsection{Polymerization of $N$-vinyltetrazoles}

Figure 5 presents the most interesting polymers obtained in terms of nitrogen-content or expected energetic output. To the best of our knowledge, polymerization of 5-nitro-1vinyltetrazole ${ }^{8}$ is unknown. However, 1-vinyltetrazoles are generally readily polymerized in free-radical conditions, with water as the solvent of choice. The activity depends on the nature of the 5-substituent. For example, 5-amino-1-vinyltetrazole 7 is less active than the unsubstituted compound due to the electron-donating character of the amino group $\left[{ }^{9},{ }^{10}\right]$. Unusually, yields of poly(5-amino-1-vinyltetrazole) 8 are slightly higher in $N, N$ dimethylformamide (DMF) than in water. Recently, emulsion polymerization gave porous monoliths of the corresponding so-called 'polyHIPEs' of 8, exhibiting remarkable mechanical properties [11].

The synthesis and polymerization of 5-(methyl)hydrazino-1-vinyltetrazole 9 have been described. It was necessary to add the initiator (AIBN) in several portions to enhance the conversion of the starting vinyl compound. However, while $9 b(\mathrm{R}=\mathrm{Me})$ yielded $85 \%$ of the corresponding polymer $\mathbf{1 0 b}$, the yield of $\mathbf{1 0 a}$ from $\mathbf{9 a}(\mathrm{R}=\mathrm{H})$ was limited to about $25-30 \%$ and the degree of polymerization was very low. The synthesis of the very nitrogen-rich azide-functionalized polymer $\mathbf{1 1}$ was attempted through diazotization of 10a. However, elemental analyses were unsatisfactory because of partial decomposition of the tetrazolylhydrazine moieties $\left.{ }^{12}\right]$.

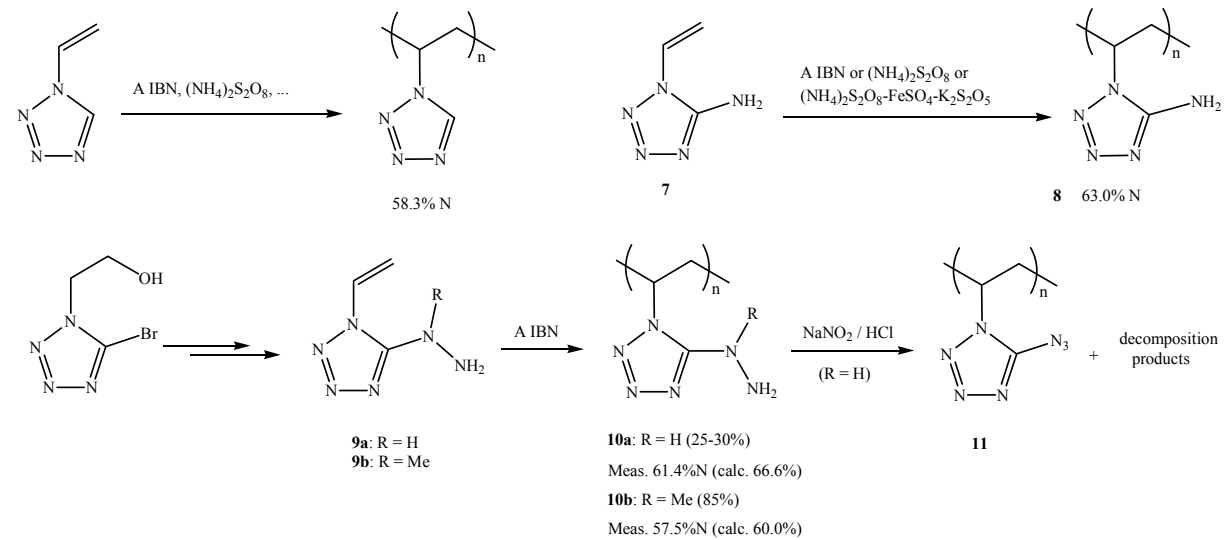

Figure 5.

The different examples cited herein highlight the high nitrogen content of polyvinyltetrazoles and their prospects as energetic compounds. In 2003, a pilot-plant production of polyvinyltetrazoles was started in two companies in Russia.

\subsection{Incorporation of tetrazole via polymer-analogous transformation}

It is well-known that tetrazoles can be obtained by addition of an azide onto a cyano derivative. This method was applied to polyacrylonitrile (PAN) in order to synthesize poly(5-vinyltetrazole) (Figure 6). 


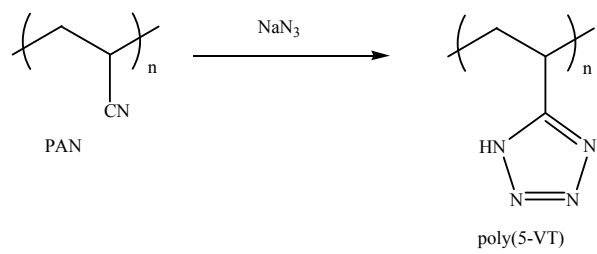

\section{Figure 6.}

When using $\mathrm{NaN}_{3} / \mathrm{NH}_{4} \mathrm{Cl}$, it was shown that higher temperatures and molecular weights of the initial PAN resulted in a higher incorporation of tetrazole moieties in the polymer $\left[{ }^{13}\right]$. Thus, at $105^{\circ} \mathrm{C}$, a PAN with a $\mathrm{Mw}$ of $180,000 \mathrm{~g} / \mathrm{mol}$ was almost completely transformed in the corresponding poly(5-vinyltetrazole) (tetrazole units: $97.5 \%$ ). The tetrazole content was estimated by 2 independent methods: weight measurements and acid-base titration. According to the authors, this poly(5-vinyltetrazole) synthesis using polymer-analogous transformation is advantageous since there is no commercial source of 5-vinyltetrazole and its synthesis is difficult.

Zinc chloride has also been used as a catalyst to carry out the desired transformation [ $\left.{ }^{14}\right]$. The best components ratio was $\mathrm{NaN}_{3} / \mathrm{NH}_{4} \mathrm{Cl} / \mathrm{RCN} 4 / 4 / 1$. Infrared and NMR spectroscopies demonstrated the total conversion of nitrile functions into tetrazoles. In addition to PAN, other nitrile-containing polymers were succesfully tetrazolated.

Poly(5-vinyltetrazole) for gas generants was also synthesized upon the action of a zinc salt $\left(\mathrm{ZnBr}_{2}\right)$ but polymerization was carried out in emulsion in the presence of a surfactant $\left[{ }^{15}\right]$. A related patent subsequently extended this water-based synthesis [ $\left.{ }^{16}\right]$. At $115^{\circ} \mathrm{C}$ tetrazolation was limited to $70 \%$, but reached $95 \%$ at $170^{\circ} \mathrm{C}$. Further reaction of the resulting poly(5vinyltetrazole) with ammonia yielded the corresponding ammonium salt 12 (Figure 7). The latter theoretically contains $61.9 \%$ of nitrogen and is therefore a promising material for gas generants. A related triaminoguanidinium salt $\mathbf{1 3}$ had been disclosed as early as in 1968 [17]. Taking into account the $6 \%$ of PAN units remaining in the starting poly-5-vinyltetrazole, a theoretical value of $69.2 \%$ of nitrogen was achieved in the salt (Figure 7).
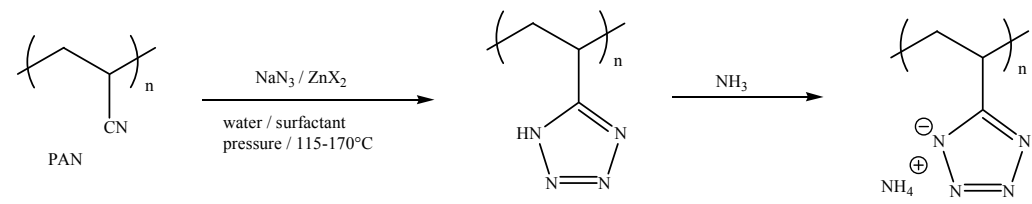

$1261.9 \% \mathrm{~N}$<smiles>CCCC(c1nnn[nH]1)C(C)(C)C</smiles>

(containing $6 \%$ of PAN)

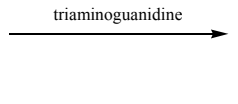<smiles>CC(C)(C)CC(c1nnn[nH]1)C(C)(C)C</smiles>

13 Meas. $69.3 \% \mathrm{~N}$ (calc. $69.2 \%$ )

Figure 7. 
All these conditions surpass earlier methods that yielded lower levels of tetrazole incorporation (see for example ref $\left[{ }^{18}\right]$ ).

Polyvinylchloride (PVC) can also be used as a polymer precursor. Upon reaction with a tetrazolate anion, the corresponding polyvinyltetrazole is formed (Figure 8). However, this method seems less practical since partial elimination of hydrogen chloride generates unsaturated fragments in the final product $\left[^{1}\right]$.

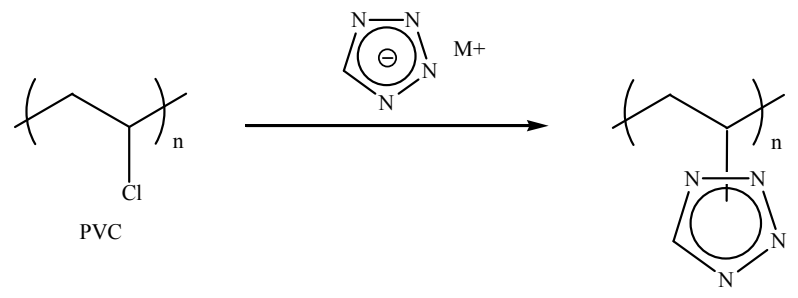

Figure 8.

\subsection{Synthesis of tetrazole-based polymers via polycondensation}

5-Chloromethyltetrazole $\mathbf{1 4}$ is an interesting substrate as it has both a nucleophilic (tetrazole $\mathrm{N}-\mathrm{H})$ and a highly electrophilic $\left(\mathrm{CH}_{2}-\mathrm{Cl}\right)$ center. In the presence of triethylamine as a base, the tetrazole ring can be deprotonated which gives rise to poly(methylenetetrazole) $\mathbf{1 5}$ in good yields $\left[{ }^{19},{ }^{20}\right]$ (Figure 9).

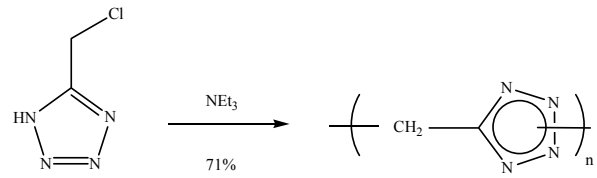

15 Meas. 67.2\% N (calc. 68.3\%)<smiles>CC(C)(C)CC(c1nnn[nH]1)C(C)(C)C</smiles>
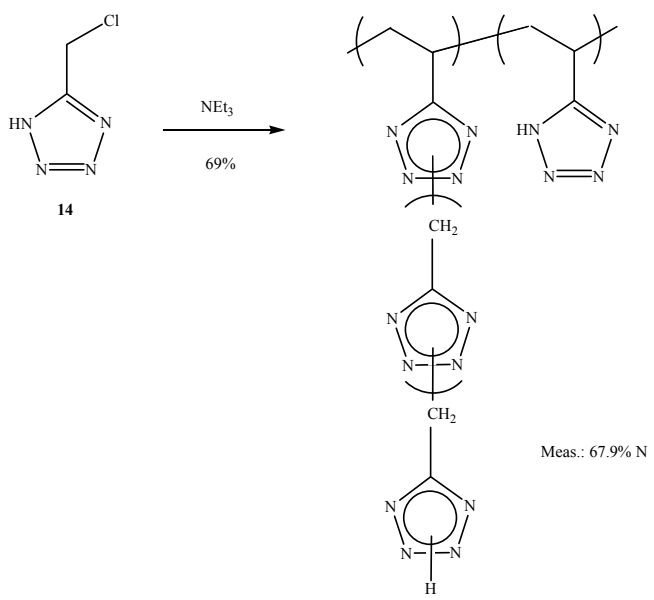

Figure 9. 
This polyalkylation product is in fact an oligomer, with $\mathrm{M}_{\mathrm{w}}$ below $2000 \mathrm{~g} / \mathrm{mol}$ (ca 15-20 units). With a measured nitrogen content of up to $67.2 \%$, it surpasses polyvinyltetrazole by almost $10 \%$. In addition, its viscous state is attained at relatively low temperatures, thus making it a very promising candidate in gas-generating systems. It should be noted that 5chloroethyltetrazole can also participate in a similar process. However, polymerization is slower and yields do not exceed $20 \%$.

The high reactivity of 5-chloromethyltetrazole $\mathbf{1 4}$ has been used to graft poly(5vinyltetrazole). Upon addition of an excess of $\mathbf{1 4}$ and triethylamine, a branched poly(5vinyltetrazole) bearing poly(methylenetetrazole) bridges was obtained in yields around $70 \%$. Ten equivalents of $\mathbf{1 4}$ produced the best results. Characterization of the polymer revealed a 6/1 ratio of methylenetetrazole vs vinyltetrazole moieties. The number of vinyltetrazole units between branching junctions was around 2. Its energetic prospects were highlighted by a very elevated density of 1.70 and a nitrogen content of $67.9 \%\left[{ }^{19,20}\right]$ (Figure 9).

A patent describes the polycondensation of various dinitriles with diazides to produce tetrazole containing polycondensates $\left[{ }^{21}\right]$. Of these, the most valuable polymer for energetic applications is the one obtained from dicyanofuroxane 15. Indeed, despite the fact that the hexamethylene spacer lowers the $\mathrm{N}$ content, a high energetic output is expected from the presence of 2 tetrazole and 1 furoxane rings in the unit of polymer $\mathbf{1 6}$ (Figure 10).

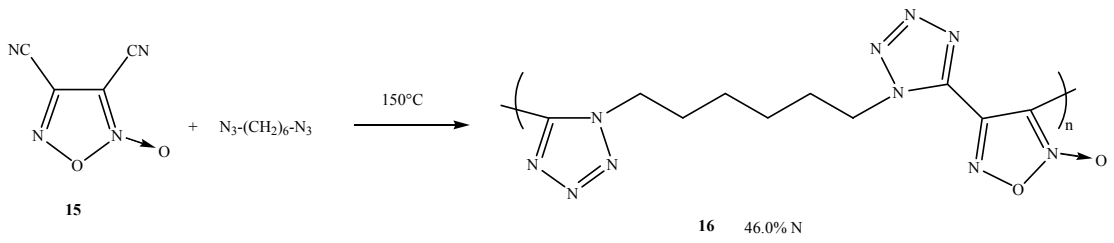<smiles>CC(C)OC(=O)Cn1nnnc1N(C)N</smiles>

17<smiles>CN(NC(C)(C)C)c1nnnn1CC(=O)C(C)(C)C</smiles>

18 Meas.: $44.9 \% \mathrm{~N}$ (calc 54.5 )<smiles>CN(N)c1nnnn1CCO</smiles>

19

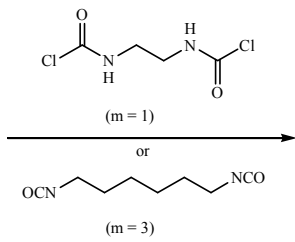

$(\mathrm{m}=3)$<smiles>CN(NC(C)(C)C)c1nnnn1CCCNC(=O)NC(C)(C)C</smiles>

20a: $m=1$
20b: $m=3$

Figure 10.

Isopropyl 2-(5-(1-methylhydrazinyl)tetrazol-1-yl)acetate 17 was polymerized at high temperature to give the corresponding polycondensate $\left.18{ }^{[2}\right]$. The yield was higher when 
working at $120^{\circ} \mathrm{C}$ rather than $140^{\circ} \mathrm{C}$, however elemental analyses still showed a lower nitrogen content than expected (44.9 instead of 54.5\%). The presence of low molecular weight polymers still bearing isopropoxy groups may account for this discrepancy.

The related monomer $N$-[1-(2-hydroxyethyl)tetrazol-5-yl]- $N$-methylhydrazine 19 was also involved in polycondensation processes. With succinyl chloride as the partner, only low molecular weights could be achieved, and results from elemental analysis were unsatisfactory. This was ascribed to the protonation of the hydrazino moieties during polycondensation. More positive results were obtained with hexamethylenediisocyanate but obviously the resulting polycondensate $\mathbf{2 0 b}$ is less attractive for energetic applications due to its lower nitrogen content $\left.{ }^{23}\right]$. Another similar polymer was recently described by the same group [ $\left.{ }^{24}\right]$ (Figure 10).

\section{Tetrazine-based polymers}

\subsection{Polyvinyltetrazines}

To the best of our knowledge, monovinyl-1,2,4,5-tetrazines are unknown, and the corresponding polyvinyltetrazines thus remain elusive compounds. However, the first member of the vinyltetrazine family, 3,6-divinyl-1,2,4,5-tetrazine 21 has been described (Figure 11).
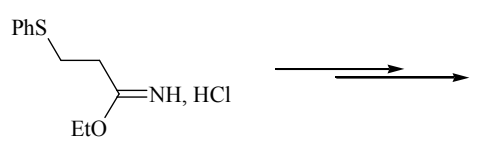
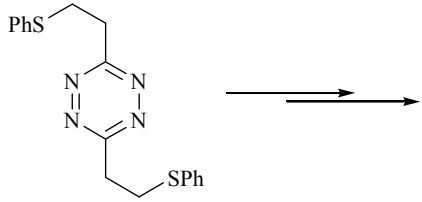

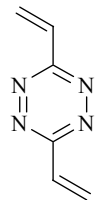

21

Figure 11.

The synthesis was achieved by using the phenylsulfanylethyl group as a masked vinyl moiety, the latter being the result of oxidation to the sulfone and elimination. Compound 21 was obtained as a volatile, pink oil that solidified in the freezer. Preliminary studies showed that 21 exhibited a limited stability at high temperatures and in the presence of radicals, which obviously precludes its use in polymer chemistry. However, 3,6-divinyl-1,2,4,5tetrazine can be seen as a tetraaza analogue of the widely used 1,4-divinylbenzene and is therefore believed to be a useful building block in the synthesis of new tetrazine-based molecules and materials [25]. Further work is needed to establish the properties and reactivity of 21. These studies also open the way towards the synthesis of unsymmetrical vinyl-1,2,4,5-tetrazine compounds that may exhibit improved stability and reactivity in polymerization conditions.

\subsection{Synthesis of tetrazine-based polymers via polycondensation}

One of the most convenient ways to construct the 1,2,4,5-tetrazine (s-tetrazine) ring is by condensation of hydrazine with a diimidate to produce the corresponding 1,2-dihydro- 
1,2,4,5-tetrazine, followed by oxidation. This strategy has been extended to the synthesis of diverse poly(phenylene-s-tetrazinylene)s by using diimidates. In order to increase the energetic prospects of such polymers, azahetaryl precursors were considered. However, the reaction of hydrazine monohydrate with pyridine-2,6-diimidate 22 did not yield the expected dihydrotetrazine polymer. Instead, the corresponding diamidrazone 23 was isolated in high yield. It is likely that the insolubility of $\mathbf{2 3}$ in THF is responsible for the uneffective polycondensation reaction. Diamidrazone 23 was used as the monomer in a microwave-assisted polycondensation to give the poly(2,6-pyridinediyl-dihydro-stetrazinylene) 24 which was further oxidized to the desired tetrazine polymer 25 using sodium nitrite/aq. $\mathrm{AcOH}\left[{ }^{26}\right]$ (Figure 12).

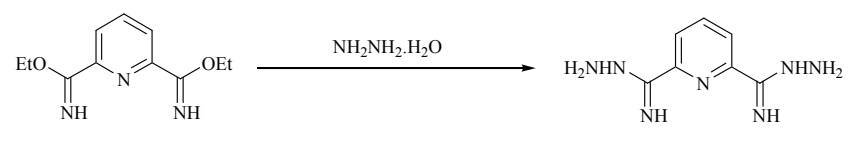

22

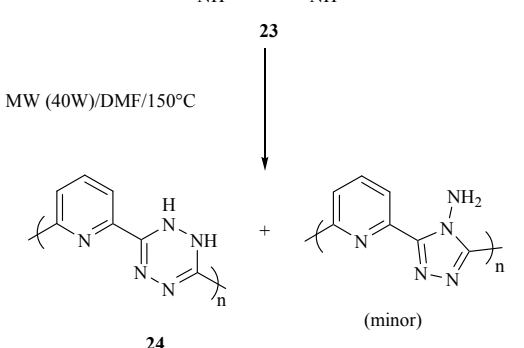

25

24

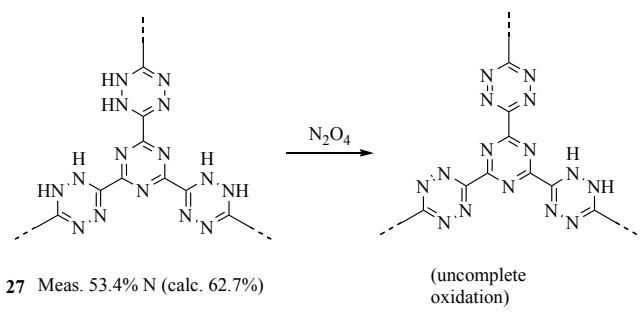

Figure 12.

Following the same strategy, the previously unknown 1,3,5-triazine-2,4,6-triamidrazone 26 was subjected to polycondensation to yield the hyperbranched polymer 27 . In this case, microwave activation was not necessary. Polymer 27 stands out as the most nitrogenated tetrazine-containing polymer, even if the measured $\mathrm{N}$ content was lower than expected, presumably due to water incorporation. A density of 1.56 was determined for 27 , which is significantly higher than the value reported for amorphous poly( $p$-phenylene) (1.11). This clearly shows how the introduction of nitrogen heterocycles in polyarylene structures is valuable in the field of energetic materials as it increases this crucial parameter. Unfortunately 27 was found unreactive to common oxidants, presumably because of its high insolubility. Only very strong oxidative conditions resulted in the formation of s-tetrazine rings, but oxidation remained uncomplete (Figure 12). 
The structures of all polymers were confirmed using ${ }^{13} \mathrm{C}$ and ${ }^{15} \mathrm{~N}$ solid state NMR $\left[{ }^{26}, 27\right]$. High-resolution spectra also indicated low amounts of 4-amino-1,2,4-triazole moieties (coming from the known rearrangement of some 1,2-dihydro-1,2,4,5-tetrazine units).

\section{Triazole-based polymers}

Synthetic strategies for $C$-vinyl- and $N$-vinyltriazoles (1,2,3- or 1,2,4-triazoles) are essentially the same as the ones presented above for vinyltetrazoles. The preparation and polymerization of vinyltriazoles have been reviewed in $2008\left[{ }^{28}\right], 2003\left[{ }^{29},{ }^{30}\right]$ and $1974\left[{ }^{31}\right]$.

\subsection{1,2,4-Triazole-based polymers}

\subsubsection{Poly(N-vinyl-1,2,4-triazole)s}

Figure 13 presents the most interesting polymers obtained in terms of nitrogen content or expected energetic output.
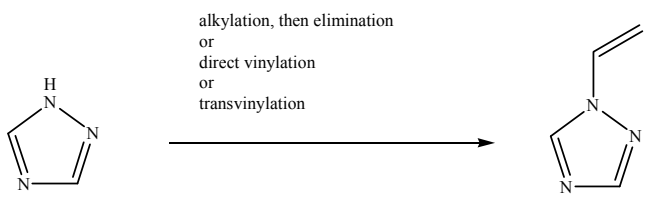

28<smiles>Nc1nc[nH]n1</smiles>

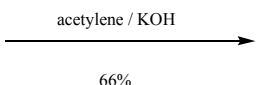

$66 \%$<smiles>O=[N+]([O-])c1nc[nH]n1</smiles>

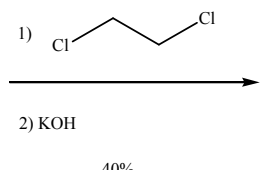

33

$40 \%$
29

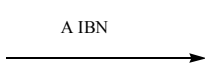

A IBN<smiles>C=Cn1cnc(N)n1</smiles>

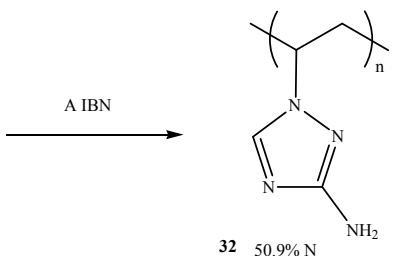

A IBN / DMF<smiles>CC(C)(C)CC(n1cncn1)C(C)(C)C</smiles>

$30 \quad 44.2 \% \mathrm{~N}$

$3250.9 \% \mathrm{~N}$

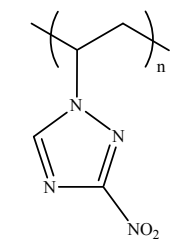

$35 \quad 40.0 \% \mathrm{~N}$

Figure 13.

1-Vinyl-1,2,4-triazole 29 was readily polymerized in free-radical conditions, and the process was more efficient in the presence of water. However, it was less active than 1-vinyl-1,2,3triazole. This trend in activity was found to correlate with the corresponding Hammet constants $\left[{ }^{29}\right]$. Poly(1-vinyl-1,2,4-triazole) 30, obtained in sufficiently aqueous media, was essentially insoluble in water or organic solvents. This polymer is a well-established 
compound that may be interesting in numerous applications. Recently, open-cell porous monoliths of poly(1-vinyl-1,2,4-triazole) cross-linked with a low amount of $\mathrm{N}, \mathrm{N}$ methylenebisacrylamide were prepared (Figure 14). They exhibited interesting mechanical properties due to the presence of water in the polymer structure, as evidenced by NMR [ $\left.{ }^{32}\right]$.

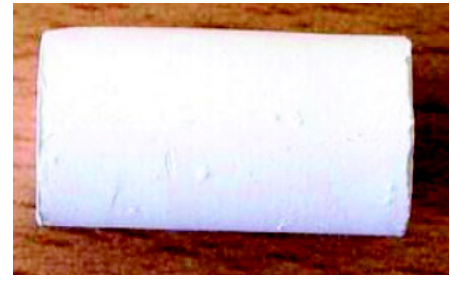

\section{Figure 14.}

For the synthesis of 3-amino-1-vinyl-1,2,4-triazole 31, the classical transvinylation using vinyl acetate in the presence of cuprous chloride was ineffective. The product was obtained through the reaction of acetylene in a basic medium at high temperature [33] (Figure 13). The presence of the amino group resulted in some changes compared to the unfunctionalized derivative: the polymerization activity was three times lower, and poly(3-amino-1-vinyl1,2,4-triazole) 32 was soluble in water [ $\left.{ }^{34}\right]$. The nitrogen content was also significantly improved to $50.9 \%$, with a density of 1.30-1.36 equalling that of polyglycidyl azide.

Poly(3-nitro-1-vinyl-1,2,4-triazole) 35 is also a useful target due to the expected output from the nitro group. Alkylation of 3-nitro-1,2,4-triazole 33 with dichloroethane followed by dehydrochlorination gave a mixture of 1- and 4-vinyltriazole. The former (34) was polymerized in DMF and gave a polymer that was soluble only in highly polar solvents [ $\left.{ }^{35}\right]$ (Figure 13).

\subsubsection{Poly(C-vinyl-1,2,4-triazole)s}

The strategy involving the construction of the vinyl fragment through dehydrohalogenation, dehydration or deamination is also applicable for the synthesis of $C$-vinyl-1,2,4-triazoles $\left[28,{ }^{36}\right]$. Another approach is the use of the Wittig reaction, exemplified below for salts of poly(C-vinyl-1,2,4-triazole).

\subsubsection{Energetic poly(vinyl-1,2,4-triazole)s salts}

To further increase the potential of poly(1-vinyl-1,2,4-triazole), protonation with energetic inorganic or organic acids was investigated (Figure 15). Polymerization of protonated 1vinyl-1,2,4-triazole 36 was successful only with the nitric or perchloric acid-protonated product, since the presence of nitro functionalities in the organic acids tended to inhibit polymerization. Moreover, only about $70 \%$ of the nitrate or perchlorate anions remained after polymerization. However, radical polymerization of 1-vinyl-1,2,4-triazole 29 in DMF followed by protonation produced a series of energetic salts of poly(vinyl-1,2,4-triazole) 38 . Elemental analyses established that the molar degree of substitution of anions was between 
48 and $92 \%\left[{ }^{37}\right]$. Thus this process represents a convenient way of improving the performances of the well-known poly(vinyl-1,2,4-triazole) 37.

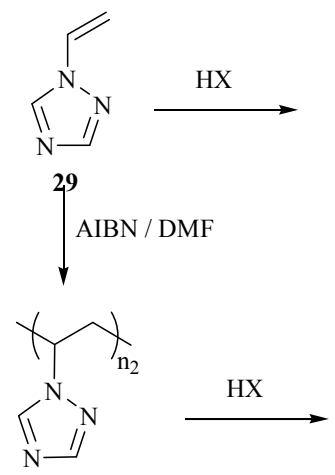

37<smiles>[X][C@H]1CNCN1C=C</smiles>

36
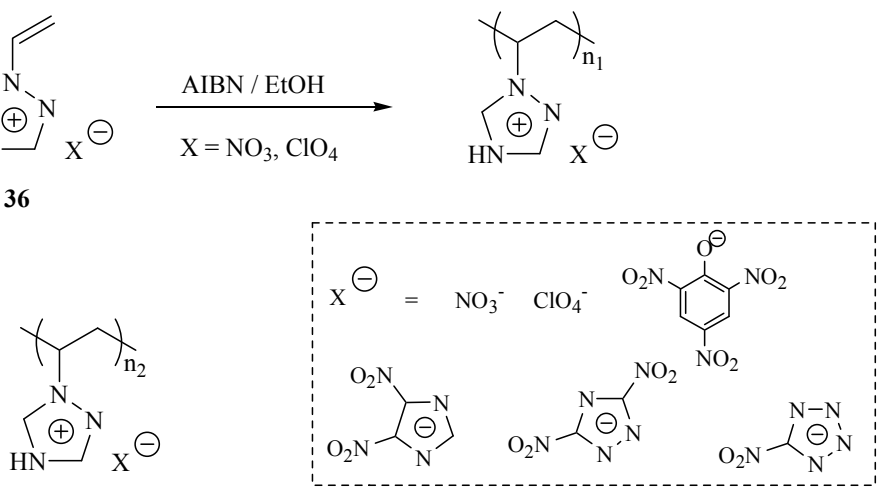

38

Figure 15.

The equivalent work in the poly( $C$-vinyl-1,2,4-triazole $)$ series is also disclosed in a patent $\left.{ }^{38}\right]$. Salts (e.g., the ammonium salt) of 3(5)-bromomethyl-1,2,4-triazole 39 were converted to the 3(5)-vinyl derivatives $\mathbf{4 0}$ following a Wittig-type methodology. Free-radical or cationic polymerization produced the corresponding salt of poly(3(5)-vinyl-1,2,4-triazole) 41 (Figure 16). This compound has been used as a fuel in gas-generating compositions.

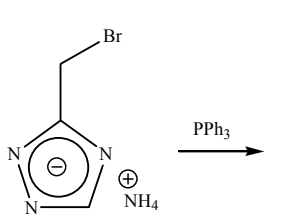

39
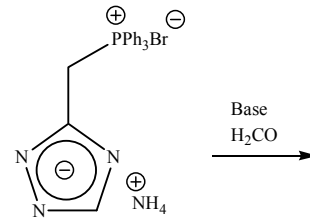

Figure 16.

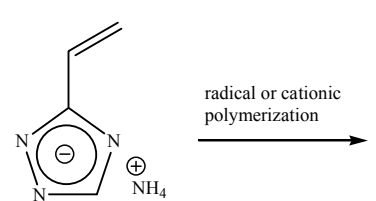

40

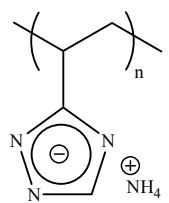

$41 \quad 50.0 \% \mathrm{~N}$

\subsubsection{Incorporation of 1,2,4-triazole via polymer-analogous transformation}

Energetic heterocyclic analogues of the well-known polyglycidyl azide (GAP) have been prepared via substitution of the chlorine atom of polyepichlorhydrin $\mathbf{4 2}$ by the anion of 3(5)nitro-1,2,4-triazole 43-Na [ $\left.{ }^{39}\right]$. The reaction proceeded in an almost quantitative fashion (residual chlorine: $0.1-0.4 \%$ ) when carried out in high-boiling solvents at $100-130^{\circ} \mathrm{C}$. Proton NMR enabled the determination of N-1 vs N-2 alkylation at the triazole ring, and a marked selectivity (9/1) towards the N-1 substituted polymer was found (Figure 17). The introduction of sodium azide together with the nitrotriazole salt resulted in a copolymer of glycidylazide and N-glycidyl-3-nitro-1,2,4-triazole. 


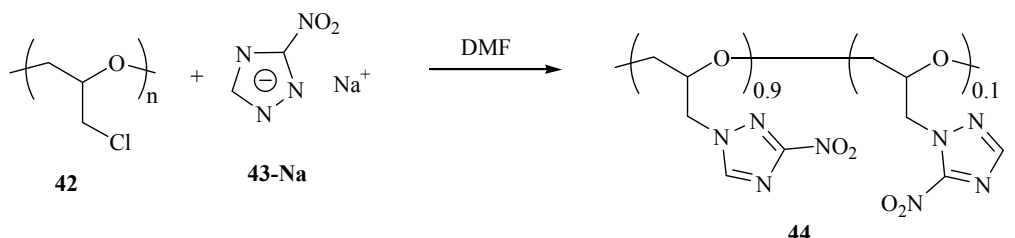

Figure 17.

\subsubsection{Synthesis of 1,2,4-triazole-based polymers via polycondensation}

Among the few 1,2,4-triazole-based condensation polymers known $\left[{ }^{40}\right]$, the most promising as energetic materials are poly(4-amino-1,2,4-triazole)s $\left[{ }^{41}\right]$. The latter can be commonly obtained through isomerization of poly(dihydrotetrazine)s 45 , following the general scheme depicted in Figure 18. This process is closely related to the one mentioned in the tetrazine section of this chapter.

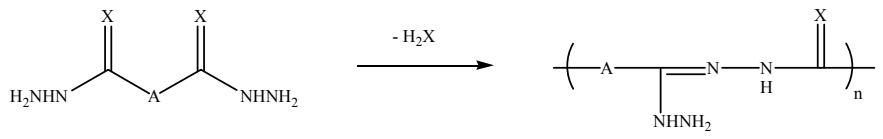

$\mathrm{X}=\mathrm{NH}, \mathrm{O}$

$\mathrm{A}=$ alkylene, arylene

$-\mathrm{H}_{2} \mathrm{X}$<smiles>CC(C)(C)c1nnc(C(C)(C)C)n1N</smiles>

46<smiles></smiles>

rearrangement<smiles>CN(C)c1nnc(C(C)(C)C)n(C(C)(C)C)[nH][nH]1</smiles>

45

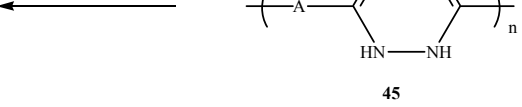<smiles>CC(C)(C)Cc1nnc(C(C)(C)C)n1N</smiles>

46-C2 $\quad 50.9 \% \mathrm{~N}$

\section{Figure 18.}

Polymer 46-C2 stands out as the most nitrogenated member of this family with a calculated $\mathrm{N}$ content of $50.9 \%$. Even though the first synthesis of 46-C2 dates back to 1954 [ $\left.{ }^{42}\right]$, interest for this polymer or similar derivatives has been maintained for a long time for diverse applications $\left[{ }^{43},{ }^{44}\right]$.

Another polycondensate incorporating 4-amino-1,2,4-triazole units has been mentioned in a patent. The synthesis is based on the simultaneous condensation of 3,5-dihydrazino-4amino-1,2,4-triazole 47 and diaminoguanidinium azide 48 with formaldehyde/glyoxal (4/1) $\left[{ }^{45}\right]$. The exact structure of the resulting polymer 49 is not disclosed but has been claimed to provide a N/C ratio of 2.3 (Figure 19). 
<smiles>NNc1nnc(NN)n1N</smiles><smiles>N=C(NN)NN</smiles>

Figure 19.

It should also be noted that 3-amino-1,2,4-triazole can be subjected to electrooxidation to yield films of the corresponding polymer $\left[{ }^{46},{ }^{47}\right]$. However, the use of these films seems to be limited to corrosion protection applications and they obviously cannot be implemented as energetic materials.

\subsection{1,2,3-Triazole-based polymers}

\subsubsection{Poly(N-vinyl-1,2,3-triazole)s}

1-Vinyl-1,2,3-triazole 50 can be classically synthesized via reaction of 1,2,3-triazole with acetylene in the presence of a catalyst $\left[{ }^{48}\right]$, or by transvinylation with vinyl acetate $\left.{ }^{49}\right]$. Another possibility is the construction of the 1,2,3-triazole ring through 'click' chemistry between a functionalized azide and (substituted) acetylene, followed by elimination. A recent synthesis $\left[{ }^{50}\right]$ following this scheme is presented in Figure 20. By using vinylacetylene in this approach, 1,5-divinyl-1,2,3-triazole 52 can be obtained [ ${ }^{51}$ ]. 1-Vinyl-1,2,3-triazole itself is highly active in classical free-radical polymerization $\left[{ }^{29}\right]$ and can also be polymerized to 51 using reversible addition-fragmentation and transfer (RAFT) conditions [50], but 5-nitro-1vinyl-1,2,3-triazole $53\left[{ }^{49}\right]$ is inert in this process (see below).
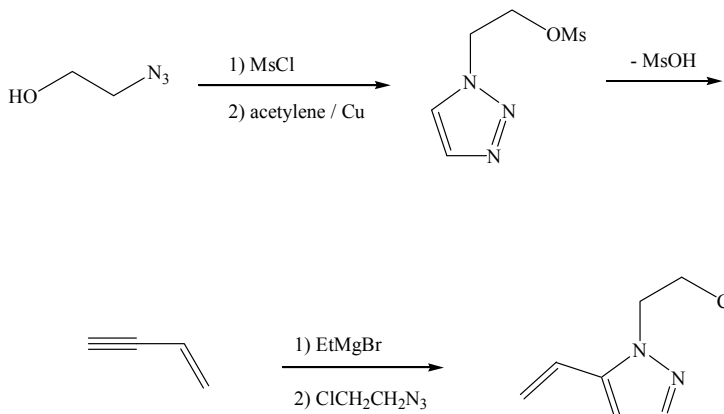<smiles>C=Cc1cnnn1CCCl</smiles>

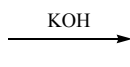<smiles>C=Cn1nncc1[N+](=O)[O-]</smiles>

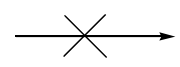<smiles>C=COC(C)=O</smiles><smiles>CC(C)(C(=O)O)C(=O)O</smiles>

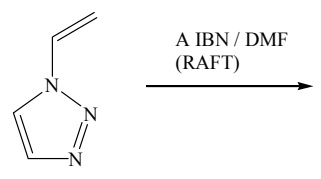

50

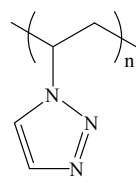

$5144.2 \% \mathrm{~N}$<smiles>C=Cc1cnnn1C=C</smiles>

52<smiles>CC(C)(C)CC(n1nncc1[N+](=O)[O-])C(C)(C)C</smiles>

Figure 20. 


\subsubsection{Poly(C-vinyl-1,2,4-triazole)s}

4-Vinyl-1,2,3-triazole 56 has been obtained through 'click' chemistry with different acetylene and azido derivatives. A recent example describes the use of vinylacetylene 54 and azidomethyl pivalate 55 as starting materials [52]. This monomer is also active in radical polymerization [ ${ }^{53}$, but less than its $N$-vinyl congener. Poly(4-vinyl-1,2,3-triazole) 57 has also been synthesized by deprotection of poly[4-vinyl-1(4-methoxybenzyl)-1,2,3-triazole] 58 [ $\left.{ }^{54}\right]$ (Figure 21).

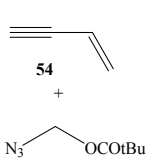

55
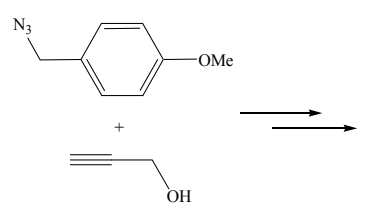

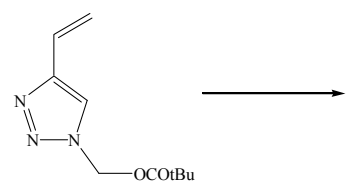

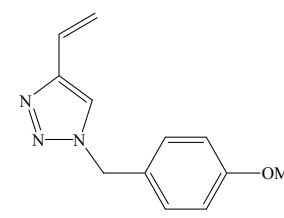

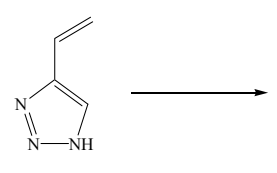

56

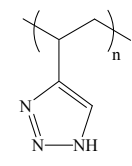

57

Figure 21.

\subsubsection{Incorporation of 1,2,3-triazole via polymer-analogous transformation}

Reaction of the sodium salt of 4(5)-nitro-1,2,3-triazole 59-Na with polyvinylchloride (PVC) afforded poly(1-vinyl-4-nitro-1,2,3-triazole) 60. By using at least 2 equivalents of 59-Na at $120^{\circ} \mathrm{C}$ for 1 day, a complete substitution of the chloride functions could be achieved as demonstrated by elemental analysis showing 39.9\% of N (calc. 40.0\%) [55] (Figure 22).

This is the only method rendering it possible to obtain this nitrated polymer since it cannot be synthesized through polymerization of 1-vinyl-4-nitro-1,2,3-triazole 53. As a matter of fact, in 53, the nitro group acts as an inhibitor under radical and ionic conditions, which is apparently not the case for the isomeric 3-nitro-1-vinyl-1,2,4-triazole 34 (see above).

The same chemistry was applied to copolymers of vinylchloride and 2-methyl-5-vinyltetrazole to yield the corresponding nitro-1,2,3-triazole containing copolymers 61a-b. Copolymer 61a exhibited a measured $\mathrm{N}$ content of $47.2 \%$.

Similarly, the salt 59-Na was used to quantitatively substitute the chlorine atoms on polyepichlorhydrin 42. As in the nitro-1,2,4-triazole series (see above), a mixture of isomers was obtained, but the selectivity was reversed: the N-2 isomer was the major one $(60 \%)\left[{ }^{56}\right]$ (Figure 22).

\subsubsection{Synthesis of 1,2,3-triazole based polymers via polycondensation}

The well-established reaction of an azide with an alkyne, that has been extensively used for monomeric 1,2,3-triazole compounds, can be further extended to the synthesis of polymers. 
<smiles>CCC(Cl)C(C)(C)CC</smiles>

PVC<smiles></smiles>

59-Na<smiles>CC(C(C)(C)C)C(C)(C)n1cc([N+](=O)[O-])nn1</smiles>

60 Meas. $39.9 \% \mathrm{~N}$ (calc. $40.0 \%$ )<smiles>CCC(C)C(CC(C)(C)C)C(C)(C)C(C)(C)C</smiles>

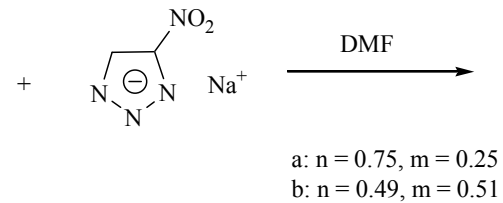<smiles>CCCC(c1nnn(C)n1)C(C)(C)CC(C(C)C)n1cc([N+](=O)[O-])nn1</smiles>

61 a: Meas. $47.2 \% \mathrm{~N}$ (calc. $48.2 \%$ )<smiles>CC(C)(C)CC(CCl)OC(C)(C)[18OH]</smiles>

42<smiles>CC(C)(C)CC(Cn1ncc([N+](=O)[O-])n1)OC(C)(C)C</smiles>

62<smiles>CC(C)CC(Cn1nncc1[N+](=O)[O-])OC(C)C</smiles>

Figure 22.

Thus, (azidoalkyl)- or (azidoaryl) acetylenes were polymerized without catalyst to afford materials that were presumed to contain 1,4- and 1,5-substituted 1,2,3-triazole rings in a random distribution [ $\left.{ }^{57}\right]$. The most interesting compound for energetic applications was polymer 64, obtained from 3-azido-1-butyne 63 (Figure 23).
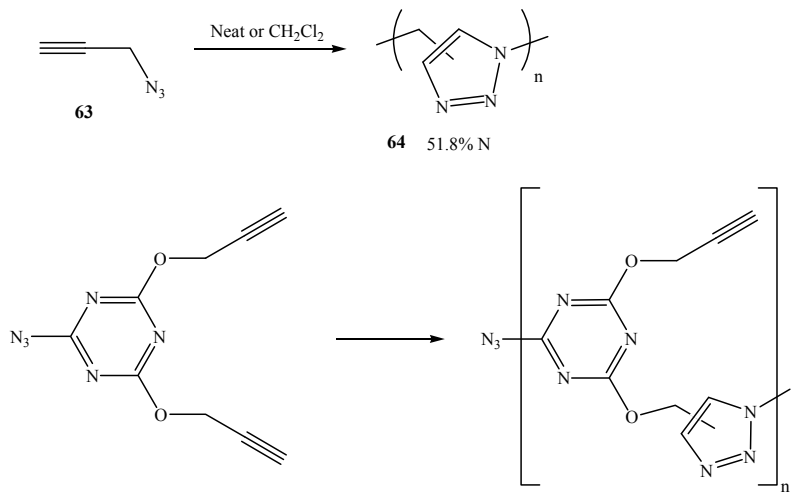

65

\section{Figure 23.}

Similarly, an azido-1,3,5-triazine containing propargyl ether was used as the monomer. Of the different conditions (bulk, solution, with or without catalyst or heating), polymerization in bulk without catalysts was found to be the best way to minimize decomposition reactions 
and formation of by-products [58]. The hyperbranched product 65 offers an original combination of both triazine and triazole rings, although the nitrogen content was obviously lowered by the remaining propargyl ethers moieties .

\section{Triazine-based polymers}

To the best of our knowledge, vinyl-1,2,4-triazines are unknown. Some poly-1,2,4-triazines have been obtained by polycondensation [ $\left.{ }^{59}\right]$, however their nitrogen content is much too low for them to be considered as energetic materials. This section will thus focus on polymers containing 1,3,5-triazines (s-triazines), which have been studied for a long time. Ref $\left[{ }^{60}\right]$ is a comprehensive review of earlier work.

\subsection{Polyvinyl-1,3,5-triazines}

2-Vinyl-1,3,5-triazine $\left.67{ }^{[61}\right]$ has been prepared from 1,3,5-triazine 66 but it seems that interest in it faded quickly due to the ease of hydrolysis. 2-Vinyl-4,6-disubstituted-1,3,5triazines were claimed to be more stable $\left[{ }^{62}\right]$.
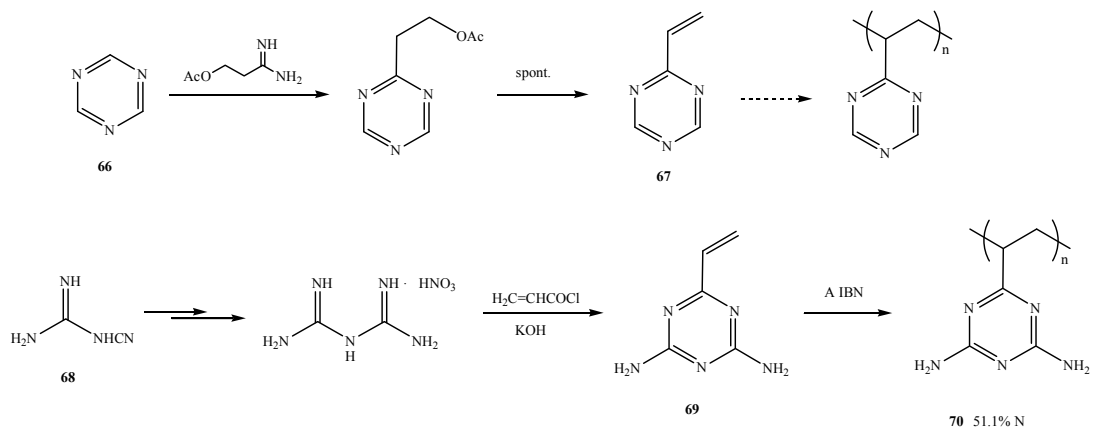

Figure 24.

2,4,6-Trivinyl-1,3,5-triazine would also be an interesting compound (as a nitrogencontaining cross-linker) but the reported yield for its synthesis is poor [ ${ }^{61}$. In fact, the most valuable vinyltriazine is 2,4-diamino-6-vinyl-1,3,5-triazine 69, which can be prepared in 2 steps from dicyandiamide $68\left[{ }^{63}\right]$. Compound 69 has been polymerized in free-radical conditions, either by using potassium persulfate in water [ $\left.{ }^{63}\right]$ or AIBN in DMSO or DMF $\left[{ }^{64}\right]$. The calculated $\mathrm{N}$ content of poly(2,4-diamino-6-vinyl-1,3,5-triazine) 70 exceeds 50\% (Figure 24).

\subsection{Synthesis of 1,3,5-triazine-based polymers via polycondensation}

Amino-substituted triazines bearing a leaving group have been heated to obtain the corresponding homopolycondensates. A linear polytriazinylamine 72 was formed from 2,4diamino-6-phenoxy-1,3,5-triazine 71 [65], whereas a hyperbranched structure $\mathbf{7 4}$ resulted from 2-amino-4,6-dichloro-1,3,5-triazine 73 since it was impossible to control the reaction in 
the sense that only one chlorine atom reacted [66] (Figure 25). Although no elemental analyses were reported to ascertain the structures, these products are believed to exhibit a high nitrogen content. Compound $\mathbf{7 4}$ is claimed to approach a cross-linked structure, which is corroborated by its limited degree of softening.<smiles>Nc1cc(Oc2ccccc2)nc(N)n1</smiles>

71<smiles>Nc1nc(Cl)nc(Cl)n1</smiles>

73<smiles>CCNc1nc(C)nc(Cl)n1</smiles><smiles>C=C=C</smiles><smiles>CNc1ncnc(NC)n1</smiles>

75<smiles>[CH2-]C</smiles><smiles>Nc1nc(N)nc(Nc2nc(N)nc(Oc3ccccc3)n2)n1</smiles>

72<smiles>Cc1nc(C)nc(N(c2nc(C)nc(C)n2)c2nc(C)nc(N(C)C)n2)n1</smiles>

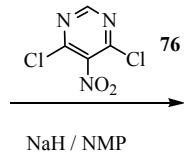<smiles>CN(C)c1ncnc(N(C)c2ncnc(C(F)(F)F)c2[N+](=O)[O-])n1</smiles>

$77 \quad 43.1 \% \mathrm{~N}$

Figure 25.

In a similar fashion, 2,4-bis(methylamino)-1,3,5-triazine 75 was reacted with 4,6-dichloro-5nitro-pyrimidine 76 in the presence of a base. Modest molecular masses were obtained $(1000-10000 \mathrm{~g} / \mathrm{mol})$, as confirmed by the presence of end-chain NHMe signals in NMR spectra $\left[{ }^{67}\right]$. However, polymer 77 is still of interest thanks to the presence of the energetic nitro group in addition to a reasonable nitrogen content (Figure 25).

Aminoalkyl units can also serve as linkages between triazine rings, as exemplified by the commercially available polymer $\mathbf{7 8}$, which has been used as a charring agent in flameretardant compositions [ $\left.{ }^{68}\right]$ (Figure 26).

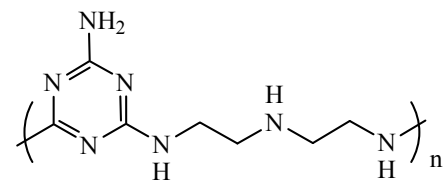

78

\section{Figure 26.}

Melamine-formaldehyde resins constitute a well-known class of compounds. Not surprisingly, related polymers can also be considered as derivatives with high nitrogen contents. For example, the reaction of trichloromelamine $\mathbf{7 9}$ with formaldehyde followed by 
dehydrochlorination has been claimed to give a structure in which triazine rings are linked together through carbodiimide or dihydrocarbodiimide units [ $\left.{ }^{69}\right]$ (Figure 27).<smiles>ClNc1nc(Cl)nc(NCl)n1</smiles>

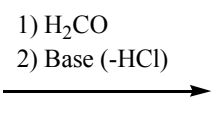<smiles>Cc1nc(C)nc(N=C=NC(C)(C)C)n1</smiles>
or<smiles>Cc1nc(C)nc(NC=NC(C)(C)C)n1</smiles>

Figure 27.

The chemistry shown above in the case of polytriazinylamines has also been widely explored for the synthesis of polytriazinylethers. The latter are obviously less attractive in terms of nitrogen content. However, commercially available nitro-containing diols are valuable compounds when one wishes to incorporate explosophoric functions in the final material. Thus, 2-nitroresorcinol $\mathbf{8 0}$ was reacted with trichlorotriazine $\mathbf{8 1}$ (cyanuric chloride) in the presence of a base to produce a cross-linked polymer 82 with triazine units and nitro groups (Figure 28). The interfacial conditions readily employed for such polycondensations were naturally adapted for the synthesis of porous polyHIPEs of this material $\left[{ }^{70}\right]$ (see tetrazole and triazole-based polymers for other examples of high-nitrogen polyHIPEs). The chemical structure should be similar to the one obtained by cyclotrimerization of 1,3dicyanato-2-nitrobenzene $\left[{ }^{71}\right]$.<smiles>Cc1nc(Cl)nc(Cl)n1</smiles>

80<smiles></smiles><smiles>Cc1nc(Cl)nc(Cl)n1</smiles>

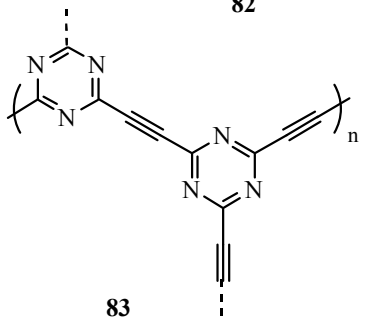

Figure 28.

It should also be noted that carbon dinucleophiles are effective in polycondensation reactions with cyanuric chloride. Thus, sodium carbide enabled the construction of cross-linked architectures 83 in which triazine rings were connected by ethynylene moieties [ $\left.{ }^{72}\right]$ (Figure 28).

Another well-known way to obtain triazine compounds is the cyclotrimerization of nitriles. However, only scarce examples deal with azaheterocyclic nitriles. 2,6-dicyanopyridine 84 
was converted at high temperatures, in the presence of zinc chloride, to a porous framework 85 with alternating pyridine and triazine nuclei [73]. The measured $\mathrm{N}$ content was slightly below that expected (27.7 vs 32.5\%) (Figure 29)
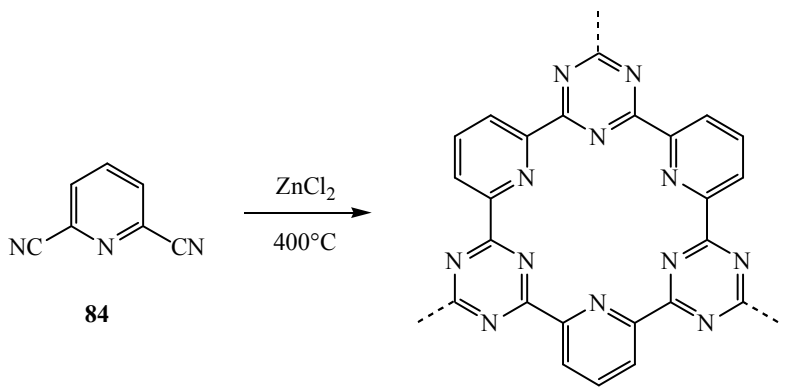

85

\section{Figure 29.}

The quest for graphitic forms of carbon nitride $\left(\mathrm{g}-\mathrm{C}_{3} \mathrm{~N}_{4}\right)$ has stimulated a vast amount of research in order to find suitable molecular precursors. With a calculated nitrogen content of $60.9 \%, \mathrm{C}_{3} \mathrm{~N}_{4}$ surely has its place in this overview, although only a few precursors lead to materials approaching the theoretical N/C ratio due to the presence of hydrogen or oxygen. The structure of $\mathrm{C}_{3} \mathrm{~N}_{4}$ is still under consideration, but surely involves 1,3,5-triazine moieties. Many useful references are provided to the reader in $\left[{ }^{74}\right]$. Theoretical as well as characterization results have indicated that tri-s-triazine structures $\mathbf{8 6}$ rather than s-triazines would be intermediates towards g- $\mathrm{C}_{3} \mathrm{~N}_{4}\left[{ }^{75}\right]$ (Figure 30).

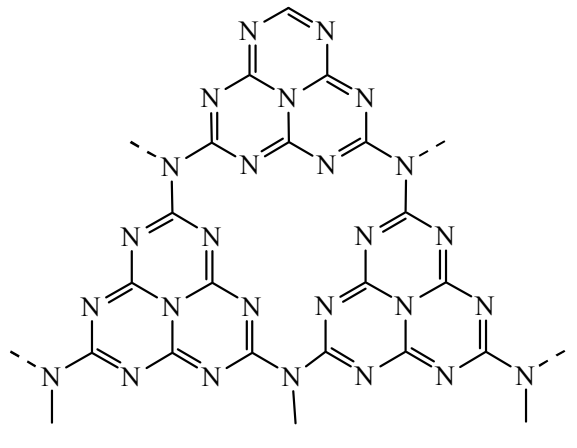

86

Figure 30.

\section{Miscellaneous}

Azide salts of bis(aminoguanidinium) compounds can be condensed with formaldehyde to produce the corresponding polymers $\mathbf{8 7 a - b}$ (Figure 31 ). Thanks to the azide groups and the intrinsically nitrogen-rich aminoguadinium moieties, the nitrogen content of these 
polycondensates was remarkably high, up to $77 \%\left[{ }^{45},{ }^{76}\right]$. A related copolymer incorporating 4-amino-1,2,4-triazole units has already been described in the triazole section.

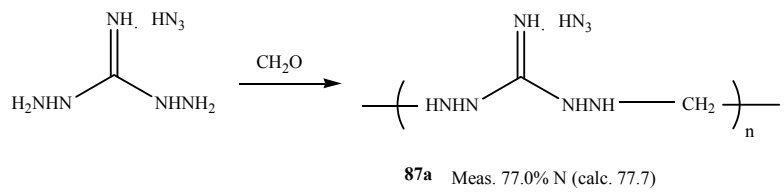<smiles>N=C(N)NCCNC(=N)N</smiles>

$2 \mathrm{HN}_{3}$<smiles>CC(C)(C)CNNC(=N)NCCNC(=N)NNC(C)(C)C</smiles>

87b Meas. $71.8 \% \mathrm{~N}$ (calc. 72.0$)$

Figure 31.

Gaseous cyanogen (NC-CN) is a promising monomer as it shows a $\mathrm{C} / \mathrm{N}$ ratio of $1 / 1$. Studies have been devoted to its polymerization and given rise to so-called paracyanogen, either through chemical $\left.{ }^{77}\right]$ or photochemical $\left.{ }^{78}\right]$ methods. The determination of the exact structure of the polymer is a difficult task and a number of different hypotheses have been postulated (Figure 32). This work is made complicated by the incorporation of solvent or water/oxygen during the polymerization process, which leads to a significant presence of oxygen in the elemental analyses. Therefore, the theoretical figure of $50 \%$ of nitrogen can hardly be obtained. However, certain reaction conditions have enabled the synthesis of materials exceeding $40 \%$ of $\mathrm{N}$.

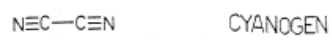<smiles>CNC(C#N)NC(C)C#N</smiles><smiles>Cc1nc2nccnc2nc1Nc1nc(N)c(N)nc1Cl</smiles>
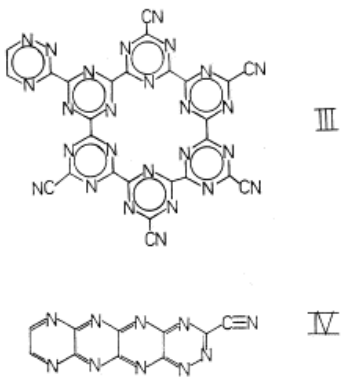

Figure 32. (from ref [78]) 


\section{Conclusions}

This review highlights a number of azaheterocycles-based polymer structures containing a high content of nitrogen, frequently around $50 \%$. In some cases, over $60 \%$ and $70 \% \mathrm{~N}$ can be achieved, mainly in tetrazole-based materials. The presence of additional explosophoric groups such as nitro may also be encountered in such polymers which strengthens the interest in using them for energetic applications. The diversity of the described structures renders it possible to foresee a wide range of properties for these energetic materials. Consequently, a great opportunity is offered to select the appropriate material for a specific application in this field. Certain patents cited in this survey show that some of these polymers have already been exploited, and many other applied high-nitrogen polymers will surely see the light in the future.

\section{Author details}

Eric Pasquinet

CEA-DAM Le Ripault - BP16 - F-37260 Monts, France

\section{References}

[1] Kizhnyaev VN, Pokatilov FA, Vereshchagin LI (2008) Carbochain Polymers xith Oxadiazole, Triazole, and Tetrazole Cycles. Polym. sci. ser. C. 50:1-21.

[2] Kizhnyaev VN, Vereshchagin LI (2003) Vinyltetrazoles: Synthesis and Properties. Russ. chem. rev. 72: 143-164.

[3] Henry RA (1967) Process for Synthesis of Vinyltetrazole Monomers. US Pat. 3,383,389.

[4] Buzilova SR, Shulgina VM, Sakovich GV, Vereshchagin LI (1981) Synthesis of Vinyl Derivatives of Tetrazole. Chem. heterocycl. comp. 17:960-963.

[5] Aleshunin PA, Dmitrieva UN, Ostrovskii VA (2011) Vinyltetrazoles: II. Synthesis of 5Substituted 1(2)-Vinyltetrazoles. Russ. j. org. chem. 47: 1882-1888

[6] Vereshchagin LI, Buzilova SR, Mityukova TK, Proidakov AG, Kizhnyaev VN, Il'ina VV, Sukhanov GT, Gareev GA, Bogens AK (1986) Synthesis of Functionally Substituted NVinyltetrazoles. Russ. j. org. chem. 22: 1777-1783.

[7] Vygodskii YS, Mel'nik OA, Kazakova EV, Shaplov AS, Komarova LI, Kizhnyaev VN (2008) Free-Radical Polymerization of C-Vinyltetrazoles: Effect of the Nature of Ionic Solvents. Polym. sci. ser. B. 50: 193-197.

[8] Koldobskii GI, Soldatenko DS, Gerasimova ES, Khokhryakova NR, Shcherbinin MB, Lebedev VP, Ostrovskii VA (1997) Tetrazoles: XXXVI. Synthesis, Structure, and Properties of 5-Nitrotetrazole. Russ. j. org. chem. 33:1771-1783.

[9] Kizhnyaev VN, Kruglova VA, Shivernovskaya OA, Ratovskii GV, Protasova LE, Vereshchagin LI (1991) Electronic Structure and Activity of Vinyltetrazoles in Radical Homopolymerization. Izv. akad. nauk. SSSR ser. khim. 2234-2238.

[10] Kizhnyaev VN, Kruglova VA, Ivanova NA, Ratovskii GV, Buzilova SR, Gareyev GA (1989) The Radical Polymerization of N-Vinyltetrazoles. Polym. sci. USSR. 31: 2728-2734. 
[11] Youssef C, Backov R, Treguer M, Birot M, Deleuze H (2010) Preparation of Remarkably Tough PolyHIPE Materials via Polymerization of Oil-in-Water HIPEs Involving 1Vinyl-5-Aminotetrazole. J. polym. sci. A: polym. chem. 48: 2942-2947.

[12] Klapötke TM, Sproll SM (2010) Nitrogen-Rich Polymers Based on 5-Bromo-1-vinyl-1Htetrazole. Eur. j. org. chem. 1169-1175.

[13] Huang M-R, Li X-G, Li S-X, Zhang W (2004) Resultful Synthesis of Polyvinyltetrazole from Polyacrylonitrile. React. function. polym. 59: 53-61.

[14] Tsarevsky NV, Bernaerts KV, Dufour B, Du Prez FE, Matyjaszewski K (2004) WellDefined (Co)polymers with 5-Vinyltetrazole Units via Combination of Atom Transfer Radical (Co)polymerization of Acrylonitrile and Click Chemistry-Type Postpolymerization Modification. Macromolecules 37: 9308-9313.

[15] Miller CG, Williams GK (2005) Gas Generant and Synthesis. PCT Appl. WO 2005/118715 A2.

[16] Miller CG, Williams GK (2006) Water-Based Synthesis of Poly(tetrazoles). PCT Appl. WO 2006/050444 A1.

[17] Torley RE, Sprague GS (1968) Triaminoguanidinium Salts of 5-Vinyltetrazole Polymers and a Method for Their Preparation. US Pat. 3,397,186.

[18] Gaponik PN, Ivashkevich OA, Karavai VP, Lesnikovic AI, Cheshavina NI, Sukhanov GT, Gareev GA (1994) Polymers and Copolymers Based on Vinyltetrazoles. 1. Synthesis of Poly(5-vinyltetrazole) by Polymer-Analogous Conversion of Polyacrylonitrile. Angew. makromol. chem. 219: 77-88.

[19] Kizhnyaev VN, Pokatilov FA, Vereshchagin LI (2007) Branched Tetrazole-Containing Polymers. Polym. sci. ser. A. 49: 28-34.

[20] Kizhnyaev VN, Pokatilov FA, Vereshchagin LI, Smirnov AI (2006) Method for Preparing Polymethylenetetrazoles. Pat. RU 2318003 C2.

[21] Carpenter WR (1968) Tetrazole Polymers. US Pat. 3,386,968.

[22] Klapötke TM, Sproll SM (2008) Synthesis and Characterization of Nitrogen Rich, Energetic Polymers Based on Tetrazoles. Proc. New trends in research of energetic materials, Pardubice, 796-804.

[23] Banert K, Klapötke TM, Sproll SM (2009) Synthesis of N-[1-(2-Hydroxyethyl)- $1 H$ tetrazol-5-yl]-N-methylhydrazine as Polymeric Precursor. Eur. j. org. chem. 275-281.

[24] Klapötke TM, Sproll SM (2010) Investigation of Nitrogen-Rich Energetic Polymers Based on Alkylbridged Bis-(1-methyl-tetrazolylhydrazines). J. pol. sci. A: polym. chem. 48: 122-127.

[25 Pican S, Lapinte V, Pilard JF , Pasquinet E, Beller L, Fontaine L, Poullain D (2009) Synthesis of 3,6-Divinyl-1,2,4,5-Tetrazine, the First Member of the Elusive Vinyltetrazine Family. Synlett 5: 731-734.

[26] Sagot E, Le Roux A, Soulivet C, Pasquinet E, Poullain D, Girard E, Palmas P (2007), Synthesis of Linear and Hyperbranched Tetrazine-Based Polyhetarylenes Assemblies with High Nitrogen Content. Tetrahedron 63: 11189-11194.

[27] Palmas P, Girard E, Pasquinet E, Caron T, Poullain D (2007) Spectral Assignments for $1 \mathrm{H}, 13 \mathrm{C}$ and $15 \mathrm{~N}$ Solution and Solid-State NMR Spectra of s-Tetrazines and Dihydro-sTetrazine Derivatives. Magn. reson. chem. 45: 65-71. 
[28] Kizhnyaev VN, Pokatilov FA, Vereshchagin LI (2008) Carbochain Polymers xith Oxadiazole, Triazole, and Tetrazole Cycles. Polym. sci. ser. C. 50:1-21.

[29] Tsypina NA, Kizhnyaev VN, Pokatilov FA, Smirnov AI (2003) N-Vinyltriazoles in Radical Polymerization. Polym. sci. ser. B. 45:41-44.

[30] Kizhnyaev VN, Vereshchagin LI, Verkhozina ON, Pokatilov FA, Tsypina NA, Petrova TL, Sukhanov GT, Gareev GA, Smirnov AI (2003) Triazole and Tetrazole Containing Energetic Compounds. Proc. ICT conference, 75: 1-11.

[31] Smets GJ (1974) Some New Polymers, Their Syntheses and Properties. 24th Plenary main. sect. lect. int. congr. pure. appl. chemical. 1: 1-23. CA 1976:463755.

[32] Audouin F, Birot M, Pasquinet E, Besnard O, Palmas P, Poullain D, Deleuze H (2011) Preparation, Solid-State NMR and Physico-Chemical Characterization of Surprisingly Tough Open Cell PolyHIPEs Derived From 1-Vinyl-1,2,4-Triazole Oil-in-Water Emulsions. Macromolecules 44: 4879-4886.

[33] Skvortsova GG, Domnina ES, Makhno LP, Voronov VK, Taryashinova DD, Chipanina NN (1973) Structure and Properties of 3-Amino-1-vinyl-1,2,4-triazole. Khim. geterosikl. soedin. 11: 1566-1569.

[34] Kizhnyaev VN, Pokatilov FA, Adamova LV, Zelenkov LE, Smirnov AI (2008) Polymerization of 1-Vinyl-3-amino-1,2,4-triazole and Some Properties of Related Polymers. Polym. sci. ser. B 50: 16-19.

[35] Attarian OS, Asratian GV, Eliazian GA, Darbinian EG, Matsoian SG (1986) Synthesis and Polymerization of Vinyl Derivatives of 1,2,4-Triazole, 3-Nitro-1,2,4-triazole and Tetrazole. Arm. khim. zh. 39: 630-635.

[36] Overberger CG, Yuen PS (1970) Esterolytic Catalyses by Triazoles. J. am. chem. soc. 92: $1667-1671$.

[37] Xue H, Gao H, Shreeve JM (2008) Energetic Polymer Salts from 1-Vinyl-1,2,4-Triazole Derivatives. J. polym. sci. A: polym. chem. 46: 2414-2421.

[38] Williams GK, Burns SP, Mishra IB (2005) Gas Generating Commpositions. PCT Appl. WO 2005/035466 A2.

[39] Sukhanova AG, Sakovich GV, Sukhanov GT (2010) Reaction of 3-Nitro-1,2,4-Triazoles with Alkylating Agents. 7. N-Monoalkylation by Monocyclic $\alpha$-Oxide Polymers. Chem. heterocycl. comp. 46: 478-482.

[40] Korshak VV, Teplyakov MM (1969) Synthesis of Polymers with Azole Rings. Progr. polim. khim. 198-251. CA 1970:13074.

[41] Nishikubo T, Hasegawa M (1987) Polyaminotriazoles. In: Kroschwitz JI, editor. Encyclopedia of Polymer Science in English. New York: Wiley. pp. 507-514.

[42] Fisher JW (1954) Polyaminotriazoles as Fiber-Forming Materials. J. appl. chem. 4: 212219.

[43] Jorgensen B, Liepins R (1983) Fluorescers and Filters of Unusual Chemical Composition for Low-Energy X-Ray Measurements. J. vac. sci. technol. A. 1: 894-896.

[44] Suzuki T, Yamamoto K, Hino Y, Harada Y, Nagura H (1995) Secondary Batteries with Nonaqueous electrolytes. Jap. Pat. JP07169459.

[45] Oja PD, Creek W, Niles ET (1968) High Nitrogen Polymers Prepared by Reacting Aldehydes with Aminoguanidines, Tetrazoles, or Triazoles. US Pat. 3,375,230. 
[46] Qafsaoui W, Takenouti H (2010) Corrosion Protection of 2024-T3 Aluminium Alloy by Electro-Polymerized 3-Amino-1,2,4-triazole in Sulphate Solution Containing Chloride. Corros. sci. 52: 3667-3676.

[47] Trachli B, Keddam M, Takenouti H, Srhiri A (2002). Protective Effect of Electropolymerized 3-Amino 1,2,4-triazole Towards Corrosion of Copper in $0.5 \mathrm{M}$ NaCl. Corros. sci. 44: 997-1008.

[48] Voychtcheva OV, Galkine VD, Mikhantyev BI, Chatalov GV (1973) Vinylation of 1,2,3Triazole. Izv. Vyssh. Ucheb. Zaved, Khim. Tekhnol. 16: 1913-1914.

[49] Kizhnyaev VN, Pokatilov FA, Tsypina NA, Ratovskii GV, Vereshchagin LI, Smirnov AI (2002) Synthesis of N-Vinyl-1,2,3-triazole Derivatives. Russ. J. org. chem. 38: 1056-1059.

[50] Nulwala H, Burke DJ, Khan A, Serrano A, Hawker CJ (2010) N-Vinyltriazoles: a New Functional Monomer Family through Click Chemistry. Macromolecules 43: 5474-5477.

[51] Vereshchagin LI, Tikhonova LG, Maksikova AV, Gavrilov LD, Gareev GA (1979) Synthesis of Acyl- and Vinyl-substituted 1,2,3-Triazoles. 15: 544-549.

[52] Sanghi S, Fassbender B, Tuominen M, Brunklaus G, Spiess HW, Coughlin EB (2010) Proton Conducting Properties of Poly(4-vinyl-1H-1,2,3-triazole). Polym. Preprints 51: 76-77.

[53] Wouters G, Smets G (1982) Copolymerization of C-Vinyltriazoles and C-Vinyltetrazole with Vinyl Monomers. Makromol. chem. 183: 1861-1868.

[54] Zhou Z, Li S, Zhang Y, Liu M (2006) 1H-1,2,3-Triazole Based Polymer Materials for Proton Exchange Membranes. Polym. mater. sci. eng. 94: 609.

[55] Petrova TL, Kizhnyaev VN, Tsypina NA, Vereshchagin LI, Smirnov AI (2002) Method for Preparing Vinylnitrotriazole Polymers. Pat. RU 2261873 C2.

[56] Sukhanov GT, Sukhanova AG, Filippova YV (2004) Selectivity of N-Monoalkylation and Exhaustive Alkylation in Synthesis of Polymers of N-Glycidyl Derivatives of 3-Nitro-5R-1,2,4- and 4-nitro-1,2,3-triazoles. CA 2006:9757.

[57] Baldwin MG, Johnson KE, Lovinger JA, Parker CO (1967) 1,3-Dipolar Cycloaddition Polymerization of Compounds Containing Both Azido and Acetylene Groups. Polym. lett. 5: 803-806.

[58] Malkov GV, Shastin AV, Estrin YI, Badamshina ER, Mikhailov YM (2008) Synthesis and Characterization of the Nitrogen-Rich Hyperbranched Polymers - Poly $([1,2,3]$-Triazole[1,3,5]-Triazine)s. Propellants explos. pyrotech. 33: 431-436.

[59] Hergenrother PM (1975) Poly-as-triazines. J. macromol. sci. revs. macromol. chem. C13: 189-218.

[60] Pankratov VA, Vinogradova SV (1972) Polytriazines. Russ. chem. rev. 41: 66-82.

[61] American Cyanamid Co (1963) Triazine Derivatives and Polymers Thereof. US Pat. $935,787$.

[62] American Cyanamid Co (1958) Substituted s-Triazine and Method of Preparation. US Pat. 2,845,422.

[63] Overberger CG, Michelotti FW (1958) The Preparation of Polymers and Copolymers from Vinylpyrimidines and Triazines. J. am. chem. soc. 80: 988-991.

[64] Yuki Y, Hiramatsu N, Kakurai T, Noguchi T (1969) Polymerization of 2,4-Diamino-6Vinyl-s-Triazine. Kobunshi Kagaku 26: 134-140. 
[65] Thurston JT, Schaefer FC, Dudley JR, Holm-Hansen D (1951) Cyanuric Chloride Derivatives. V. Reaction of Alkoxy-s-Triazines and Aryloxy-s-Triazines with Amines. J. am. chem. soc. 73: 2992-2996.

[66] Ehlers GFL, Ray JD (1964) Synthesis and Characterization of Poly-s-Triazinyleneimides. J. polym. sci. A. 2: 4989-5003.

[67] Courvoisier C, Mercier R, Pasquinet E, Poullain D, Palmas P (2004) Synthèse de Polymères Hétérocycliques Azotés à Partir de Précurseurs Triaziniques. Journées de chimie organique, Palaiseau.

[68] Liu Y, Deng C-L, Zhao J, Wang J-S, Chen L, Wang Y-Z (2011) An Efficiently HalogenFree Flame-Retardant Long-Glass-Fiber-Reinforced Polypropylene System. Polym. degrad. stab. 96: 363-370.

[69] Komatsu T (2000) Heat-Resistant (Dihydro)Carbodiimide Group-Containing Triazine Polymers. JP Pat. 2000-63467.

[70]Audouin F, Birot M, Pasquinet E, Deleuze H, Besnard O, Poullain D (2008) Synthesis of Porous Materials by 2-Nitroresorcinol/Cyanuric Chloride Thermal Polycondensation in Emulsion. J. appl. polym. sci. 108: 2808-2813.

[71] Grigat E, Schminke H-D, Pütter R (1965) Verfahren zur Herstellung von Hochmolekularen Polytriazinen. BRD Pat. 1190184.

[72] Paushkin YM, Aleksandrova VA, Lunin AF, Pisarenko TA (1969) Polycondensation of Cyanuric Chloride with Disodium Acetylide. Doklady. akademii. nauk SSSR 184:863866. CA 1969:106920.

[73] Kuhn P, Antonietti M, Thomas A. (2008) Porous, Covalent Triazine-Based Frameworks Prepared by Ionothermal Synthesis. Angew. chem. int. ed. 47: 3450-3453.

[74] Schmidt CL, Jansen M (2010) New Directions in Carbonitride Research: Synthesis of Resin-Like Dense-Packed C3N4 using a Hydrogen-Free Precursor. J. mater. chem. 20:4183-4192.

[75] Jürgens B, Irran E, Senker J, Kroll P, Müller H, Schnick W (2003) Melem (2,5,8-Triaminotri-s-triazine), an Important Intermediate during Condensation of Melamine Rings to Graphitic Carbon Nitride: Synthesis, Structure Determination by X-ray Powder Diffractometry, Solid-State NMR, and Theoretical Studies. J.am. chem. soc. 125: 1028810300.

[76] Niles ET, Oja PD, Pannell CE (1969) High Nitrogen Containing Monomeric 1,2-Ethylene Bis(aminoguanidine) Compound-Aldehyde Condensation Polymer. US Pat. 3,408,331.

[77] Jenneskens LW, Mahy JWG, Vliestra EJ, Goede SJ, Bickelhaupt F (1994) Structural Studies on Paracyanogen and Paraisocyanogen. J. chem. soc. faraday trans. 90: 327-332.

[78] Cataldo F (1999) On Cyanogen Photopolymerization. Eur. polym. j. 35: 571-579. 